\section{BOOK REVIEW}

\begin{tabular}{|l|l}
\hline & PRACTICAL DENTAL LOCAL \\
ANAESTHESIA, 2ND EDITION \\
J. G. Meechan \\
Quintessence \\
price e28.00; pp 140 \\
ISBN 9781850972044
\end{tabular}

This textbook forms part of the successful series of quintessential books for general dental practitioners. Local anaesthesia is very relevant to any dental speciality and forms an essential part of providing painless, effective treatment to patients. Historically, the vast majority of textbooks have been written and published in America and it goes without saying that these books are of fine quality. However, it is refreshing to acknowledge the work of a British oral surgeon, who wrote this excellent book. Dr John Meechan is internationally recognised for his contribution to this field and is the lead researcher in local anaesthesia studies in Newcastle Dental School, as well as collaborating internationally with the University of Toronto, Canada, the University of Campinas, Brazil and Yeditepe University, Istanbul. The book is addressed to a wide target audience, from undergraduate dental students, through to general dental practitioners, senior house officers, registrars and established specialists.

It is divided into nine chapters: pharmacology and anatomy, instrumentation, local anaesthetic drugs, maxillary and mandibular anaesthesia, supplementary techniques, safety, trouble-shooting and a discussion on painless local anaesthesia. Each chapter opens with aims and objectives and finishes with referenced scientific articles for further reading; enabling those with a particular interest to look up the evidence-base.
A real strength of this book is the generous use of high quality images, diagrams, tables and figures which help the reader understand the principles outlined. This is particularly useful when studying the more advanced techniques such as the Akinosi-Vazirani block, mylohyoid nerve block and anterior ramus technique. For those who are preparing for postgraduate examinations such as MFDS, MJDF or international equivalent, the section on safety is particularly useful, covering common exam topics such as drug doses and medical emergencies.

The strength of this textbook is providing an easy-to-read and understandable guide to dental local anaesthesia, combining relevant best practice evidence with comprehensive explanations of current treatment methods and applicable clinical advice. In summary, I would not hesitate to recommend this book to anyone interested in this field. It covers all the essential areas surrounding local anaesthesia and provides a firm foundation for further reading, making it a valuable addition to any dentist's book shelf.

L. BOVENSIEPEN

\title{
DENTIST TRIUMPHS TO STAY ON THE DENTIST'S REGISTER
}

A dentist who was served with a notice of erasure from the Dentist's Register has defied all predictions and successfully appealed the General Dental Council (GDC) decision. Edgar Gordon was told by the GDC that he was 'unlikely to succeed' but sustained by a belief in the rule of law, he defended himself and won.

Having gone onto the Dentists Register in 1954, Mr Gordon retired from high street practice in 1988. Since 1995 he has written dentolegal reports for solicitors. Although ongoing registration is not necessarily a requirement, he elected to stay on the register. When $\mathrm{Mr}$ Gordon came to meet the deadline for making his CPD submission last October, he lacked the evidence for 48 hours of non-verifiable CPD and notice of erasure was served.

Mr Gordon was told that if he appealed orally and failed, the
Council reserved to right to ask for a costs order of $£ 1,000$ as well as the fees of their instructing Counsel at £250 an hour + VAT.

In his appeal Mr Gordon submitted evidence of 441 dento-legal reports which he maintained involved reading and referencing the dental literature. He argued successfully this constituted 'the other activities relevant to the person's practice' under the legislation governing CPD.

The committee hearing the appeal said in their determination that if Mr Gordon had attributed 15 minutes reading and referencing to each report and if this information had been provided earlier with his contemporaneous log of reports, the GDC would have considered it. The Committee concluded that it was 'unfortunate' that Mr Gordon did not provide this information to the GDC, and equally, that the GDC did not seek to ask him how much time had been attributed to each report.

Mr Gordon said: 'To consider erasing a dentist over just 48 hours of non-verifiable CPD which has neither validity or reliability seemed to me to be a nonsense. I went into the lion's den with my eyes open. There was a risk I could have been humiliated, but thanks to my experience of advocacy I was able to cross-examine the council's witness and present my arguments.'

\section{BDA UPDATE}

\section{AGM notice}

Notice is hereby given that the 65th AGM of the North Western Branch of the British Dental Association will take place on Tuesday 12 May 2015 in the Maxillo-Facial Unit, Royal Lancaster Infirmary commencing at 18.45. For further information email the secretary Mark Collinson at mscollinson@ hotmail.co.uk

Response to the launch of dental prototypes

The BDA's General Dental Practice Committee (GDPC) has responded to the Department of Health's announcement that 62 pilot practices will move forward to become prototype practices for the reformed NHS contract in England. Further prototype practices are expected to be announced in due course. The prototypes contain the discredited UDA (Unit of Dental Activity) activity measure as well as payments for capitation and quality. There will be two types of prototypes with varying UDA targets. The BDA's view is that payment should be based on capitation only. The BDA has indicated it will be reaching out to all practices that have been involved in the pilot process to offer support and assistance, as they either move forward to the prototype system or revert to previous contracting arrangements.

Peter Crooks re-elected Chair of Northern Ireland Dental Practice Committee

Peter Crooks has been re-elected as Chair of the Northern Ireland Dental Practice Committee (NI $\mathrm{DPC})$. He was re-elected unopposed. Peter has previously served two terms on NI DPC between 2010 and 2015. He qualified from Queen's University, Belfast in 1983 , is a general dental practitioner and has owned his practice in Ballymena since 1987. Peter has had a long career in dental politics and was the Chair of the Northern Local Dental Committee for three years. 